\title{
Um bebê no CAPSi: uma clínica possível
}

\section{One baby in CAPSi: a possible clinic}

\section{Pedro Moacyr C. Brandão J unior}

Mestrando do Programa de Pós-Graduação em Psicanálise da Universidade do Estado do Rio de Janeiro- UERJ, Rio de Janeiro, RJ, Brasil

\begin{abstract}
Resumo
$\mathrm{O}$ artigo debate a possibilidade de atendimento a crianças muito pequenas em um Centro de Atenção Psicossocial Infanto Juvenil (CAPSi), (Centro de Atenção Psicosocial infanto juvenil), serviço essencialmente destinado ao atendimento de crianças e adolescentes com grave sofrimento psíquico, em sua maioria psicóticos, autistas e neuróticos graves. Para tal ressaltamos a relevância e concomitantes dificuldades deste atendimento em Instituição Pública que recebe uma proporção maior de crianças com idade cronológica mais avançada. Nossa aposta é a de levar às últimas conseqüências a teoria psicanalítica para a qual o inconsciente é atemporal. Dividimos o artigo em duas partes, a primeira apresenta resumidamente a proposta de um CAPSi e a segunda discute o caso de um bebê que chega ao serviço com a suspeita diagnóstica de autismo.
\end{abstract}

Palavras-chave: CAPSi, Bebês, Autismo, Tratamento, Atemporalidade do inconsciente.

\begin{abstract}
This article debates on young children care possibilities in a CAPSi, (Centro de Atenção Psicosocial infanto juvenil) a service care substantially designated for children and teenagers with serious psychic suffering, in greater number psychotics, autistics and neurotics. In the case, we emphasize relevance and coincident difficulties about this care on Public Institution, which receives a greater proportion of advanced chronological age children. Our bet is take to last consequences the psychoanalytical theory, which for the unconscious is timeless. We divided the article in two parts: first, debates a CAPs proposal, and second, discusses a baby's case who came to a service care with diagnosis suspect of autism.
\end{abstract}

Keywords: CAPSi, Babies, Autism, Care, The unconscious timeless. 
O objetivo do presente artigo é discutir sobre os impasses e possibilidades do atendimento em um Centro de Atenção Psicossocial infanto juvenil (CAPSi), privilegiando o atendimento a crianças muito pequenas, que na maioria das vezes ainda não falam, casos em que os técnicos geralmente se questionam se o trabalho deveria ser voltado para questões específicas do desenvolvimento dessas crianças ou se resumiria ao atendimento dos pais. O que fazer quando essas crianças chegam aos serviços? Qual seria o trabalho possível diante de crianças que se encontram em um momento bastante precoce de sua estruturação subjetiva? Qual a função do CAPSi no atendimento desses casos?

Com o caso clínico que apresentaremos, tentaremos responder a essas perguntas e pensar em um manejo possível no atendimento a bebês, de forma a estabelecer uma articulação entre a proposta de recepção e de intervenção nos casos com o trabalho no CAPSi e com as diretrizes do SUS-Sistema Único de Saúde. Para isso dividimos o artigo em duas partes, a primeira tenta definir o trabalho desenvolvido pelas equipes de Saúde Mental no CAPSi e a especificidade do tratamento com crianças; e a segunda discute o caso de um bebê que chega ao serviço com a suspeita diagnóstica de autismo.

\section{O CAPSI : outra lógica de atendimento}

Os CAPS vêm introduzir um atendimento diferente do oferecido nos hospitais psiquiátricos, que funcionavam sob a lógica da exclusão e da segregação. Uma vez regidos pela proposta da Reforma Psiquiátrica, os tratamentos não se resumirão à internação dos pacientes em uma instituição "fechada". Além disso, o trabalho terá o objetivo de desmedicalizar o paciente e subjetivar o atendimento. Trata-se de um dispositivo que foi criado a partir da portaria GM 224/92 do Ministério da Saúde (2004, p.243) e regulamentado pela portaria no. 336/GM de 19/02/2004 (MS, 2004, p.125).

As respostas às demandas feitas ao CAPS se baseiam na lógica de trabalho proposta pela saúde pública e pela política de Saúde Mental. São os princípios e diretrizes do SUS que nos dão o eixo a ser seguido no tratamento dos pacientes. Como o atendimento deve ser universal e integral, os casos não serão eleitos previamente, e os pacientes não serão encaminhados antes de serem ouvidos. Afinal, a saúde é direito de todos e dever do Estado, cabendo a nós servidores públicos, responsabilizarmonos pelo atendimento de quem nos procura.

O princípio de "acolhimento universal" (MS, 2005, p.12) significa "que toda e qualquer demanda dirigida ao serviço de saúde no território deve ser acolhida, isto é, recebida, ouvida e respondida". O acolhimento deve resultar em uma resposta, que não se confunde com a inserção do 
paciente para tratamento no serviço. Elia (2004) propõe quatro respostas possíveis nesse acolhimento:

1) admissão para tratamento no serviço;

2) espera para admissão em momento posterior;

3) encaminhamento para outros serviços;

4) desconstrução da demanda.

A recepção é um tema especial, pois coloca em evidência a proposta de funcionamento do serviço, define quem ficará em atendimento e como será feita a articulação com a rede. Também coloca em primeiro plano o trabalho em equipe, propondo reuniões semanais com seus integrantes. 0 trabalho não é de um só, e sim, de articulação dos vários profissionais, não só do próprio CAPS, como também da rede.

A lógica do trabalho na Saúde Mental evidencia a impossibilidade de uma proposta clínica pré-determinada para os pacientes. Desse modo, os efeitos de uma intervenção não serão os mesmos para um ou para outro paciente. $\mathrm{O}$ mesmo acontece com o diagnóstico; com a medicação (que muitas vezes nos dá a impressão que se dá por tentativa e erro) e com as propostas terapêuticas. Se cada um responde de uma determinada forma às intervenções dos técnicos, não podemos definir a priori, sem escutar o paciente, uma proposta de atendimento. O manejo do caso vai ser definido de acordo com a escuta desse sujeito que nos demanda tratamento, baseando-se no fato de que não há uma definição prévia de nosso proceder clínico. Nessa perspectiva, trata-se o doente e não a doença.

O CAPSi é um serviço de atenção diária destinado ao atendimento de crianças e adolescentes com grave sofrimento psíquico. Nessa categoria estão incluídos os sujeitos psicóticos, autistas, neuróticos graves e todos aqueles que, por sua condição psíquica, estão impossibilitados de manter ou estabelecer laços sociais.

No que diz respeito à recepção dessa clientela, o trabalho com crianças tem uma especificidade, não são elas, as crianças, que vêm nos procurar. Elas chegam através dos pais, da escola, do Conselho Tutelar, mas nunca em nome próprio, não batem na porta do CAPSi pedindo para serem atendidas, pois estão angustiadas. Essa perspectiva aproxima-se da concepção psicanalítica, na medida em que promove a separação clínica entre a demanda produzida pelo paciente ao analista, e a demanda da família que diz respeito a uma outra coisa.

Nessa vertente, dar prontamente ao paciente o que se pede por ele, seja um laudo, benefício ou o atendimento, por exemplo, não viabilizará uma terapêutica, ao contrário, quando isso é feito o que teremos como resposta é a comprovação de que atender aos pedidos previamente, sem ouvir o paciente, não soluciona o problema e corrobora para que o 
inconsciente daquele sujeito continue desconsiderado em sua manifestação.

Em um CAPSi, por exemplo, atendemos uma mãe que relatava que seus filhos estavam traumatizados por causa da morte do pai, ocorrida há cinco anos. Chamou-nos a atenção o fato de só cinco anos após a perda do pai, a mãe ter percebido o "trauma" dos filhos e sua necessidade de atendimento. Quando questionada sobre os motivos que a fizeram procurar atendimento para os filhos, revela sua intenção de viver com um companheiro, e o consequente medo do que as crianças pudessem pensar, principalmente a dificuldade de se relacionar sexualmente depois de tanto tempo. Relato que resulta em uma demanda de atendimento para ela.

Em um outro caso, uma mãe pediu transporte para levar seus filhos ao tratamento. Como se tratava de uma família em condições financeiras, de saúde e higiene muito precárias, foi providenciado junto à prefeitura um carro que pudesse buscar as crianças em casa e trazê-las ao CAPSi para serem atendidas. Pouco tempo depois essa estratégia falha, pois quando o carro chegava à sua casa, um outro motivo as impedia de ir ao tratamento. O pretenso atendimento culmina com outra demanda, desta vez é para mudar os horários, pois a mãe gosta de dormir até mais tarde e a buzina do carro incomodava seu sono.

Uma outra queixa é feita por uma mãe que não podia levar a filha ao tratamento por que esta tinha problemas para se locomover, precisava de um carro da prefeitura que a buscasse em casa, um técnico prontamente providenciou uma condução para trazer a paciente ao tratamento. Providência frustrada, pois apesar do carro, ela não aparecia na instituição, quando questionada, a mãe relata que o carro parava na porta de seu condomínio, mas não entrava. Segundo ela, a filha não poderia se locomover por um percurso de cerca de 40 metros (apesar de não apresentar lesão orgânica que comprovasse o fato).

Em entrevista conta que estava separada do marido por que descobriu que este mantinha um caso extraconjugal (esta era a terceira vez que se separava do mesmo marido, pelo mesmo motivo). Na posição de vítima de um marido que a deixou com uma filha doente, diz que "é preciso que ele veja o mal que causou à sua família, é preciso que ele se dê conta de como a filha está mal, e de como piora a cada dia". Ora, se é preciso que a filha fique doente, para quê levá-la ao tratamento? Por sua vez, a menina responde ao lugar em que a mãe a situa em seu desejo, como a filha doente que certifica a ausência do pai.

Distinguimos dois fatores que se articulam no atendimento de crianças. $O$ primeiro diz respeito à resposta à demanda de atendimento. Esta que geralmente é feita por um outro, que incomodado com alguma característica que a criança apresenta, a leva para tratamento. O segundo 
está relacionado ao laço entre o bebê e seu cuidador, ao lugar que é colocado e que responde ao Outro.

Quando o bebê nasce, desamparado como nos diz Freud, ele chora e o outro com seu desejo vem para acalmar seu pranto. Na maioria das vezes esse Outro do desejo é a mãe, que dá o seio para que esse bebê mame. Diferentemente dos animais que instintivamente procuram, para sobreviver, por qualquer mamada em um ser da sua espécie, o bebê humano depende do Outro, do desejo do outro para além da mamada. Marcado pelo desejo da mãe ou pela ausência deste, não será mais somente o seio que mata a fome o que o bebê irá procurar, entrará em jogo também a dimensão do desejo desta mãe e do lugar que a criança ocupa neste.

O bebê passa a chorar não só para suprir uma necessidade, a da fome, mas sim para demandar algo além do alimento, algo que pretende atingir o desejo daquele que alimenta. Estamos no registro da demanda de presença desse Outro que é constituído 'como tendo o 'privilégio' de satisfazer as necessidades, isto é o poder de privá-las da única coisa pela qual elas são satisfeitas". (LACAN, 1958, p. 697) Afinal "é demanda de uma presença ou de uma ausência, o que a relação primordial com a mãe manifesta, por ser prenhe desse outro a ser situado aquém das necessidades que pode suprir" (LACAN, 1958, p. 697). A satisfação da necessidade passa a ser mítica, uma vez que desde sempre o bebê esteve entregue aos desejos caprichosos do Outro.

Assim o desejo é causado, por esse eterno desencontro, eterno encontro com a falta. Por isso "o homem deseja, por que a satisfação de suas necessidades vitais passa pelo apelo dirigido a um Outro, o que de imediato altera a satisfação, transformada assim em demanda de amor" (KAUFMANN, 1996, p.118). Não há uma resposta adequada do Outro capaz de satisfazer a demanda, no entanto esta aparece como se fosse possível de ser satisfeita, mas uma vez que pudesse ser satisfeita também o desejo estaria abolido.

Logo não se deve responder à demanda da paciente dando o que ela pede, acreditando que o que ela pede é realmente o que ela "quer". O manejo pode ser outro, e consequentemente o trabalho toma outra direção, afinal sabemos que estruturalmente o que o sujeito demanda não é exatamente o que "quer". Portanto, esse manejo se dá por constatar que o que se demanda na verdade não pode ser satisfeito, que o desejo é causado por uma busca faltosa, não podendo se configurar um objeto específico do desejo. A demanda nunca será satisfeita, e na clínica podemos observar que os sujeitos, como as mães de nosso exemplo, assim que receberem o que pedem, acreditando que esta é a solução para seus problemas, farão uma nova demanda.

Não se trata postular como regra que os técnicos nunca atenderão aos pedidos de seus pacientes, mas de alertar que a resposta a ser dada pelo 
técnico não pode ser ingênua e antecipada, sem ao menos escutar o que o paciente diz. Além disso, no trabalho com crianças, corre-se o risco de igualarmos a queixa do adulto ao sofrimento da criança. No caso do atendimento a bebês, essa vertente torna-se mais complexa já que estes não falam. No entanto, nessa clínica, a escuta se refere ao lugar que esse bebê ocupa no desejo da mãe, Outro primordial, responsável pelos primeiros cuidados com a criança. As intervenções objetivam que cada um possa se responsabilizar por seu lugar de sujeito, pela resposta que deram ao desejo do Outro.

Como dissemos, nosso trabalho segue a proposta feita pelo SUS e pela política de Saúde Mental. Na portaria №. 336 (MS, 2004, p.125), que estipula as atribuições dos CAPS, este é colocado como regulador da porta de entrada, sendo articulador do território, responsável pela organização da demanda e da rede de cuidados.

Muitas vezes as crianças que recebemos no CAPSi já passaram por outros serviços, receberam diferentes diagnósticos e tentativas de tratamento. $O$ encaminhamento, algumas vezes, parece ser feito de maneira automática, segundo a qual pessoas apresentam suas queixas e um profissional decide para onde mandá-las. Geralmente faz isso dando um encaminhamento por escrito, sem ter nenhum contato com o serviço que vai receber o paciente, sem saber sequer se esse paciente realmente vai ser recebido. Nossa proposta, ao contrário, exige um "encaminhamento implicado" (MS, 2005, p.12). Não só o técnico que recebe terá que se implicar no encaminhamento, fazendo contato com quem receberá o paciente (ou com quem o está encaminhando), como terá que "Iocalizar tanto o sujeito no seu sofrimento, quanto sua implicação nos eventos psíquicos de que se queixa" (MS, 2005, p.13). O que não se resume, de maneira nenhuma, a ouvir uma certa queixa/demanda e prontamente atendê-la.

Quando a mãe de nosso exemplo se dá conta de que sua queixa em relação aos filhos na verdade tem relação com seus próprios medos, ao encaminharmos para atendimento ambulatorial, já não estamos encaminhando uma mãe preocupada com o trauma dos filhos, mas um sujeito com questões a respeito de sua sexualidade, dividida entre ser mãe e mulher.

\section{Um caso no CAPSI}

Chamaremos nosso paciente de Daniel (nome fictício), que chegou ao CAPSi quando tinha um ano e um mês de idade. Ele é encaminhado por um neurologista da rede, com o pedido de avaliação psiquiátrica (para confirmar a hipótese diagnóstica de autismo), e receber medicação adequada. Como veremos adiante, o CAPSi recebe demandas desse tipo de outros profissionais da rede, acolhe o pedido e o encaminhamento, 
mas não para simplesmente executar o que é pedido (atender a demanda) mas para problematizá-la. Neste caso, por exemplo, o CAPSi não faz avaliações diagnósticas para devolvê-la ao profissional que fez a solicitação, mas procura articular-se com o referido profissional ou serviço solicitante para trabalhar sobre o caso.

Daniel já havia passado por vários especialistas: alguns outros neurologistas, oftalmologista, otorrinolaringologista, fonoaudióloga, dermatologista, vários pediatras, e outros serviços. Segundo a mãe, parecia "ser cego e surdo", aparentemente não via as pessoas e coisas, o que a intrigava, porque apesar de não andar, ele engatinhava e não esbarrava em nenhum obstáculo. Além disso, manuseava alguns objetos (por muito pouco tempo), atendia a alguns chamados e se assustava com alguns sons. A mãe estranhava o fato de que ele podia ver e ouvir, mas ao mesmo tempo dava a impressão de que isso não o afetava.

O paciente também apresentava "doenças na pele", algumas vezes eram feridas, outras vezes caroços, sarna ou micose. Era hipotônico e não se sustentava em pé, as escoriações apareciam, eram tratadas, com isso sumiam, mas logo surgia uma outra ferida. Quando não era exatamente uma doença de pele, eram machucados provocados, desde quedas que Daniel sofria na tentativa de ficar de pé até mordidas de um cachorro que tinha em casa. Nesse caso, podemos atribuir que os sinais apresentados na esfera "motora-postural" estavam também articulados ao modo como os laços entre ele e a mãe se estabeleceram, como respondeu ao desejo do Outro.

Daniel também apresentava uma estereotipia, ficava balançando a mão na frente do rosto, como se limpasse um vidro. Na maior parte do tempo permanecia chorando no carrinho ou no colo da mãe. Ele é o terceiro filho, segundo a mãe, fruto de uma gravidez "surpresa" (sic), após a segunda gestação, estranhou que não voltou a menstruar e percebeu que estava grávida novamente. A gravidez do segundo filho já foi vivenciada como uma "surpresa" (sic), apesar de fazer uso de medicamento anticoncepcional, alega que "o remédio era de farinha" (sic). O marido não queria mais filhos, desde então seu relacionamento com ele sofreu algumas mudanças, já não era mais carinhoso e parecia não se interessar por ela.

Relata que sabia que o filho iria nascer doente, que alguma coisa a alertava para o fato de que aquele filho teria problemas. Assim nasceu Daniel, "a criança doente", como é chamado na família. A mãe atribui aos outros filhos algumas obrigações com o irmão doente, característica que justifica que ela esteja completamente investida nos cuidados com o filho mais novo. Assim estrutura sua vida, volta-se inteiramente para os cuidados com o filho. Mantém uma pasta com todos os exames, receitas e documentos de Daniel, tudo muito limpo e organizado. Dorme com ele na cama, enquanto o marido dorme em um colchonete, no chão, o medo de 
que Daniel acorde e engatinhe sozinho pela casa é a justificativa que usa para manter essa dinâmica.

Depois de determinado tempo de atendimento, Daniel começa a dormir no berço, e o marido na cama com Mara, o que trouxe muitas questões para ela. Nesse momento, podemos nomear a mãe de Daniel. A chamaremos de Mara (nome fictício), pois não mais se coloca como "a mãe do paciente autista", mas como um sujeito que fala de seus desencontros amorosos com o marido, de sua insatisfação na relação com as pessoas e de sua dificuldade de se relacionar com os filhos.

Mara queixava-se de que Daniel só chorava, e esse choro, para ela, só tinha uma resposta, ele queria colo. Queria colo mesmo que no colo não parasse de chorar. Lacan (1969), na carta a Jenny Aubry, propõe duas posições que a criança poderia ocupar diante do desejo dos pais. O sintoma da criança pode vir como resposta ao que existe de sintomático na estrutura familiar, ou como objeto da fantasia da mãe. Nessa perspectiva, Daniel responde do lugar de doente, lugar em que a mãe o situa em seu desejo. Em sua escolha forçada, Daniel, alienado no desejo da mãe, não pode responder de outra maneira que não como uma criança doente, afinal iria dar problemas antes mesmo de nascer.

Desde 1895, Freud apresenta um modo de funcionamento primitivo, o qual opera antes mesmo da introdução do eu. Descreve um organismo que busca descarregar estímulos, e uma vez encontrado um caminho de descarga, o que caracteriza a satisfação, a tendência seria que a cada acúmulo de tensão essa descarga percorresse o mesmo caminho antes facilitado. O eu, nesse momento, dependeria de um novo esforço do aparelho psíquico, seria preciso um novo investimento para sua constituição e conseqüente inibição da ação automática de descarga, que no limite é alucinatória, sem nenhum compromisso com a realidade.

Delimita um modo de operar que é anterior à consciência e uma concepção de aparelho psíquico que não se constitui a partir da realidade. Freud vai demonstrar um aparelho funcionando por condensação e deslocamento. Donde Lacan nos diz, utilizando os termos da linguística, que essa operação se dá por metáfora (substituição de um significante por outro) e metonímia (deslizamento na cadeia). Nas palavras de Lacan:

A Verdichtung, condensação, é a estrutura de superposição dos significantes em que ganha campo a metáfora [...]. A Verschiebung ou deslocamento é, mais próxima do termo alemão, o transporte da significação que a metonímia demonstra e que, desde seu aparecimento em Freud, é apresentado como o meio mais adequado do inconsciente para despistar a censura (LACAN, 1957, p. 515).

Lacan ressalta que "a relação do sujeito ao Outro se engendra por inteiro num processo de hiância" (LACAN, 1964, p.196). Referimo-nos à operação de alienação e separação, de constituição do sujeito, onde "o sujeito 
aparece primeiro no Outro, no que o primeiro significante, o significante unário, surge no campo do Outro, e no que ele representa o sujeito para um outro significante, o qual tem por efeito a afânise do sujeito" (LACAN, 1964, p.207). Ou seja, quando o sujeito aparece como sentido em um lugar, em outro é afânise, fading, desaparecimento. O primeiro significante, S1, representa o sujeito para um outro significante, S2, o sujeito é representado pelo significante binário, o Vorstellungrepräsentanz, representante da representação, que é a causa do seu desaparecimento. "É no intervalo entre esses dois significantes que vige o desejo oferecido ao balizamento do sujeito na experiência do discurso do Outro" (LACAN, 1964, p.207), onde se situa a operação de separação.

O desejo reside nos intervalos entre dois significantes primordiais, é sempre desejo do Outro e "só se constitui para o sujeito como interrogável, como referência possível à constituição de seu desejo, se for situado entre os significantes como falha, como intervalo, como falta no Outro" (MIRANDA, 2002, p.59). Duas faltas estão em questão, e o desejo se constitui na tentativa de recuperá-las; a falta no Outro e a falta no sujeito, resposta possível da primeira falta. Quando Daniel responde como doente, o faz colado nos significantes oferecidos pela mãe, sem dialetização, não há espaço entre o que a mãe diz e o que pode estar querendo dele, a resposta está dada para o paciente. Nesse caso não há divisão do Outro, o Outro não é barrado, e em princípio, a consequência é uma psicose.

Certo dia, deixei o paciente com a técnica de enfermagem enquanto atendia Mara. Ele começou a chorar muito, motivo pelo qual parei o atendimento e fui verificar o que estava acontecendo. Encontramos a técnica oferecendo coisas, tentando descobrir o que poderia interromper aquele choro, não sabia o que Daniel queria. Mara de imediato o pegou no colo, mas ele não parou de chorar.

$\mathrm{Na}$ tentativa de fazer um corte na situação que se tornava fora de controle, o peguei de seu colo, e o coloquei no chão, nesse momento ele parou de chorar, e me dando as mãos, começou a ensaiar passos. Daniel não andava sozinho, e a mãe nunca tinha percebido esse fato ou tentado ajudá-lo a andar, quando chorava automaticamente o colocava no colo. Quando isso aconteceu uma outra mãe, ao ver a cena, exclamou para Mara: "Ah ! então ele queria andar! Então ele para de chorar, não é como você me disse, que ele chora o tempo todo!". Mara fica perplexa e muito assustada com a fala dessa mãe.

Essa cena é apenas um recorte e nos serve para ilustrar um percurso de atendimento, que não está estanque dos outros atendimentos feitos a Mara e Daniel. O que queremos ressaltar é que inicialmente o choro do paciente não fazia nenhuma incógnita para a mãe, estava colado em um único significado - colo. Foi preciso que Mara pudesse supor que ali havia 
um sujeito, que poderia estar pedindo algo a mais que um colo. Ou seja, que ela não sabia mais a priori o que seu filho estava pedindo. Quando faz isso, Daniel pode minimamente aparecer como uma outra coisa, que não a criança que só chora e só quer colo, apesar de ainda doente.

Nas últimas semanas soube que Daniel está andando sozinho. Pois apesar de não ter nenhum comprometimento orgânico que justificasse, não conseguia se sustentar de pé. Este é apenas o início de um longo trabalho e os passos aqui apresentados, apesar de terem grande valor tanto para a equipe, quanto (principalmente) para Daniel e sua família, somente nos servem para exemplificar que não há como definir previamente um destino para os pacientes que nos demandam atendimento.

Notem que ao receber uma criança com uma fenomenologia clara de autismo, poderíamos ter proposto um outro tipo de atendimento. Poderíamos ter deixado Mara de lado e nos voltado para os sintomas de Daniel, que não são poucos. Poderíamos ter reduzido o tratamento ao uso de medicamentos, à estimulação motora ou a propostas pedagógicas. Mas essa não é a proposta de um CAPSi.

Acolhemos o paciente e sua família, interrompemos de alguma maneira a ida de Mara a diversos serviços, entramos em contato com esses e conversamos sobre nossa avaliação e proposta de trabalho, pois percebemos que o movimento de ir a esses lugares só servia para que ela reverberasse sobre os sintomas do filho e não falasse de si. Desse modo, - CAPSi passou a ser a referência do tratamento, que até então estava diluído nos muitos lugares em que passavam. A aposta dos técnicos da Saúde Mental é de que o paciente trace um outro caminho, que não seja mais o de "doente" que fora um dia. Trabalho feito em consonância com as diretrizes de atendimento dos CAPS, que exige uma complexidade no atendimento, onde a rede de serviços precisa ser trabalhada, e que não se resume a técnicas predeterminadas de atendimento.

Quanto à proposta de atendimento a bebês nessa Instituição, em que geralmente os casos recebidos são de crianças de idade cronológica mais avançada, concluímos que é possível uma intervenção junto ao bebê e também em relação à família como no caso de Daniel. O inconsciente é atemporal e o lugar que o sujeito ocupa no desejo do Outro, lugar determinante para a estrutura do sujeito, é definido, às vezes, antes mesmo do nascimento.

\section{Referências Bibliográficas}

ELIA, L. A construção da Rede da Atenção na Saúde Mental: articulações entre CAPS e Ambulatórios. Trabalho apresentado no 
Encontro do Fórum Nacional de Saúde Mental Infanto-Juvenil, Brasília, 2004.

FREUD, S. Projeto para uma Psicologia Científica (1895). In: $\overline{1} \overline{9} \overline{9} \bar{c}$ Obras Psicológicas Completas, Vol I. Rio de Janeiro: Imago,

LACAN, J. A instância da letra no inconsciente ou a razão desde Freud (1957). In: Escritos. Rio de Janeiro: Jorge Zahar Editor, 1998, p. 496-533. A significação do falo (1958). In: . Escritos. Rio de Janeiro:

Jorge Zahar Editor, 1998, p. 692-703.

O Seminário, livro 11: os quatro conceitos fundamentais da psicanálise (1964). Jorge Zahar Editor, 1998. . Nota sobre a criança (1969). In: . Outros Escritos. Rio de Janeiro: Jorge Zahar, 2003. p. 369-370.

Ministério da Saúde. Secretaria de Assistência à Saúde. Legislação em Saúde Mental: 1990-2004. Brasília, Editora do Ministério da Saúde, 2004.

Ministério da saúde. Princípios para uma política Nacional de Saúde Mental Infanto-juvenil. Caminhos para uma política de saúde mental infanto-juvenil. Brasília, Editora do Ministério da Saúde, 2005.

MIRANDA, E. R. Debilidade Mental e estrutura clínica. 2002. $127 \mathrm{f}$. Dissertação (Mestrado em Psicanálise) - Instituto de Psicologia, Universidade do Estado do Rio de Janeiro, Rio de Janeiro.

KAUFMANN, P. Dicionário Enciclopédico de psicanálise: o legado de Freud e Lacan. Rio de Janeiro: J orge Zahar Editor, 1996.

\section{Endereço para correspondência}

Pedro Moacyr C. Brandão J unior

Universidade I guaçuí, Av. Abílio Augusto Távora, 2134, Nova I guaçu, CEP: 26275-580, RJ, Brasil.

Endereço eletrônico: pedromoacyr@uol.com.br

Recebido em: 07/08/2008

Aceito para publicação em: 30/09/2008

Editor responsável: Luciano Elia 